\title{
IMPACT OF PHYSICIAN LED LIFE STYLE MODIFICATIONS (DIET AND DAILY STEP COUNT BY USING PEDOMETER) ON GLYCEMIC CONTROL OF PATIENTS WITH TYPE II DIABETIC
}

\author{
Rimsha Azhar, Khurshid Uttra, Andaleeb Khan, Marriam Hussain Awan, Ayesha Anwer, Muhammad Wajahat Alam Lodhi, \\ Muhammad Waleed Hassan Quershi \\ Pak Emirates Military Hospital/National University of Medical Sciences (NUMS) Rawalpindi Pakistan
}

\begin{abstract}
Objective: To determine the impact of physician led life style modifications (diet and daily step count by using pedometer) on glycemic control of type II diabetic patients

Study Design: Quasi experimental study.

Place and Duration of Study: Pak Emirates Military Hospital, Rawalpindi, Aug 2018 to Feb 2019.

Methodology: The sample population comprised of 200 diabetic patients reporting for the routine follow-up at a tertiary care hospital in Rawalpindi. Patients were divided into two groups by random method. Group A had the patients with continuation of the routine anti-diabetic medication while group received the physician led life style modifications in addition to the routine anti diabetic medication. Values of HBA1c among the groups were compared three months after the start of study.

Results: Mean age of the patients was $42.19 \pm 6.175$ years. Mean duration of DM in the study participants was $4.52 \pm 4.166$ years. Out of 115 patients were male while 85 were female. HBA1c in the intervention group was $7.96 \% \pm 0.39$ while in the control group was $7.04 \% \pm 0.81$. Difference between the two groups was statistically significant ( $p$-value $<0.01$ ).

Conclusion: This study showed a significant difference in glycemic control of patients who received physician led life style modification in addition to conventional biological treatment than those who only received the routine anti-diabetic medication. Physicians should be trained to impart this sort of education to the diabetic patients in routine diabetic clinics.
\end{abstract}

Keywords: Blood Glucose, Diabetes mellitus type 2, Life style, Glycemic contol.

This is an Open Access article distributed under the terms of the Creative Commons Attribution License (http://creativecommons.org/licenses/by/4.0), which permits unrestricted use, distribution, and reproduction in any medium, provided the original work is properly cited.

\section{INTRODUCTION}

Diabetes mellitus is one of the commonest metabolic disorders. Patients from both developed and developing countries have been affected in number of ways by this multisystemdisease ${ }^{1,2}$.

Poor glycemic control has been linked with a lot of complications including immediate, short term and long term problems ${ }^{3}$. Glycosylated hemoglobin (HBA1c) has been used as a laboratory tool to assess the glycemic control among the diabetic patients all over the world with high sensitivity and specificity 4 .

Various methods have been used to control diabetes for a long time. Biological treatment mainly revolves around various classes of oral hypoglycemic and insulin ${ }^{5}$. It is usually the main stay of treatment for this chronic illness. In addition to this hardcore biological treatment, life style modifications involving dietary changes and increase in physical activity has been nominated as first line of treatment after the diagnosis of diabetes mellitus type II has been established ${ }^{6}$.

Various types of life style modifications have been studied extensively in order to find an ideal

Correspondence: Dr Marriam Hussain Awan, Resident Medicine, Pak Emirates Military Hospital, Rawalpindi Pakistan

Received: 28 Apr 2019; revised received: 09 Oct 2019; accepted: 03 Sep 2019 combination to offer to the diabetic patients. Comparison of structured and unstructured exercise program revealed that structured exercise program has been statistically better in reducing the HBA1c levels among the diabetic patients ${ }^{7}$. A large meta-analysis was conducted to look for the efficacy of pedometer based invention among various diabetic patients of different ethnicities. Pedometer used emerged as an effective tool for physical activity among these patients and was linked with good glycemic control ${ }^{8}$. A large randomized control trial conducted in US.

Involving the modification in food and exercise patterns among the diabetics revealed that glycemic control in the intervention group was better than that of control group whoonly received the routine medication for diabetes ${ }^{9}$. Better glycemic control in this chronic illness means less chance of complications and more survival with better quality of life ${ }^{10}$.

Non pharmacological interventions in the diabetic patients work through a lot of ways. Increased utilization of calories, decrease in insulin resistance, more production of insulin, less intake of carbohydrates, neuroendocrine modifications etc have been some of the mechanisms by which it can improve the glycemic control among diabetic patients. These measures are of extreme benefit during different illnesses and thus 
augment the routine biological treatment.

Some work has been done to see the effect of diet and physical activity for the control of diabetes in Pakistani population but little data has so far been undertaken on type II diabetic patients in Pakistan to determine the effect of this very important non pharmacological intervention. This study aims to determine the impact of physician led life style modifications (diet and daily step count by using pedometer) on glycemic control of type II Diabetic patients reporting at a tertiary care teaching hospital of Pakistan.

\section{METHODOLOGY}

This quasi experimental study was conducted at a tertiary care hospital of Rawalpindi between Aug 2018 to Feb 2019. Sample size was calculated by using statistics of study of Shanghai et al. Conducted in $2013^{7}$. WHO sample size calculator was used for this purpose. Non-probability consecutive sampling technique was used. Patients of type II diabetes having HbA1c $>6.5 \%$ were included in the study. Patients between age of 25-60 years with both the genders were included in this trial. Diagnosis of type II diabetes was made by a consultant medical specialist or diabetes expert on the basis of laboratory investigation results. Patients stable on oral hypoglycemic agent with no change in past three months were included in the study. Exclusion criteria included the patients with type I diabetes or those using insulin or those who had suffered from diabetic coma in past three months. Patients with uncontrolled DM or those with comorbid HTN, IHD, RA, autoimmune illnesses, bleeding disorders, and hematological or solid malignancies were also not included in this study. Patients on corticosteroids or those with severe infection or signs of any end organ damage were also not included in the study. Patients who were pregnant or had some limb injury or orthopedic procedure in past 1 year or those using any illicit substance or suffering from a chronic psychiatric condition were also part of the exclusion criteria.

Five milliliter of venous blood was drawn from each subject and secured in two separate K2-EDTA filled plastic vacutainer tubes by venipuncture under aseptic precautions for the measurement of HBA1c. $\mathrm{HbA1c}$ was measured using high performance liquid chromatography technique ${ }^{11-16}$.

Physician led life style modifications included the planning of meals and adjusting all the nutrients according to WHO guidelines ${ }^{13}$. Restriction of alcohol and smoking was also the part of dietary strategy briefed to the patients by the physician. A routine pedometer was used to count the steps and minimum 7000 steps per day were advised to the patients by the physician ${ }^{17}$. This combination of dietary modification and use of pedometer was explained in detail by the physician to the participants of the control group.

Patients were provided with a detailed description of the study and were inducted into the study after written informed consent. Patients of type II DM were randomly divided into two equal groups via lottery method. Subjects in group A were prescribed oral hypoglycemic agents while those in group B were advised oral hypoglycemic agents plus physician led life modification including dietary modification and physical activity. Difference in the glycemic control of both the group was assessed with the help of glycosylated hemoglobin level. Socio-demographic variables were collected and entered in profroma especially designed for this randomized control trial.

All statistical analysis was performed using statistics package for social sciences version 24.0. Frequency and percentage was calculated for the gender of the patients participating in the study. Mean and standard deviation was calculated for age of the patients, duration of diabetes mellitus and HBA1c levels. Difference in mean HBA1c levels of both the groups was compared by using the student $\mathrm{t}$-test. A $p$-values were considered significant if less than or equal to 0.05 .

\section{RESULTS}

A total of 230 patients were approached to participate in the study. Five refused participation and 17 were ineligible due to exclusion criteria (2 gave history of psychoactive substance use, 3 had valvular heart disease, 2 had RA, 2 were pregnant and 8 had type 1 diabetes). Eight patients gave history of hyperosmolar non osmotic coma. Therefore 200 patients participated in this study and were divided into two equal groups via lottery method. Mean age of the patients was 42.19

\begin{tabular}{|c|c|}
\hline \multicolumn{2}{|l|}{ Age (years) } \\
\hline Mean \pm SD & $42.19 \pm 6.175$ \\
\hline Range (min-max) & $25-59$ years \\
\hline \multicolumn{2}{|l|}{ Gender } \\
\hline Male & $115(57.5 \%)$ \\
\hline Female & $85(42.5 \%)$ \\
\hline Duration of Diabetes & $4.52 \pm 4.166$ \\
\hline Mellitus & 12 months - 15 years \\
\hline \multicolumn{2}{|l|}{ Body Mass Index } \\
\hline Normal & $111(55.5 \%)$ \\
\hline Obese and over weight & $89(44.5 \%)$ \\
\hline
\end{tabular}


\pm 6.175 years. Mean duration of DM in the study participants was $4.52 \pm 4.166$ years. One hundred and fifteen $(57.5 \%)$ patients were male while $85(42.5 \%)$ were female. Demographic profile of patients has been summarized in table-I. HBA1c in the intervention group was $7.96 \% \pm 0.39$ while in the control group was $7.04 \%$ \pm 0.81 . Table-II depicts that difference between the two groups was statistically significant ( $p$-value 0.001 ).

Table-II: Comparison of HBA1c levels of group A (medication only) and group B (medication plus life style modification).

\begin{tabular}{c|c|c|c}
\hline & Group A (n=100) & Group B (n=100) & $p$-value \\
\hline HBA1c\% & $7.96 \pm 0.39$ & $7.04 \pm 0.81$ & $<0.001$ \\
\hline
\end{tabular}

\section{DISCUSSION}

Ours is a developing country with a limited hea1th budget ${ }^{18}$. Focus of our health professionals should be early recognition and cost effective intervention in all the illnesses. Singhani et al in their analysis has proved that diabetes is a chronic illness which involves lifelong treatment and life style modifications ${ }^{12}$. Our findings were not very different from them. Dalay in diagnosis or poor glycemic control has been linked with poor outcome and increase rates of complications 19. A lot of work has been going on to cater for the pharmacological side of treatment ${ }^{5}$. Various new treatment options have emerged in the last decade ${ }^{5}$. Despite all the new interventions traditional approach of life style modifications still hold a vital place in the treatment options due to least number of side effects and cost effectiveness ${ }^{6}$. This randomized control trial was planned with the rationale to see the impact of these vital non pharmacological interventions on the glycemic control of the affected individuals.

Our results supported this assumption and dietary modifications told by the physician according to the WHO guidelines helped the patients in maintaining the glycemic control. Similar results have been generated in the studies done in other parts of the world $13,20,21$. Metabolic illnesses routinely involve the dietary treatments as substrate for most of the reactions in our body is derived from the diet we take during our meals. Diabetes is no exception to this rather it revolves around the intake of carbohydrates and their utilization, assimilation and excretion from the body. Whenever this balance is disturbed, the patient becomes symptomatic and is prone to the end organ damage. Therefore in addition to maintain the deficit in homeostasis by the pharmacological treatment, controlling the diet can also alleviate the problem faced in this metabolic disorder.
Our study showed positive results regarding this phenomenon and those patients who completed 7000 steps per day had better glycemic control than the control group. Past literature has also shown favorable results and pedometer has emerged as an effective intervention that exerts positive effect on the glycemic control of individuals 8,17 . Pedometer is an interesting device which helps in keeping the check of the daily physical activity of the patients. When the treating physician advise this intervention to the patient and make it part of the treatment, the patient use it religiously and complete the required number of steps. This physical activity when continued for the desired period of time shows its effect on the glycemic control of the patients.

Reduction in BMI could be achieved by the life style modifications already mentioned in our study so indirect effect on BMI could also result in the good glycemic control and produce desirable effects in the target population regarding their disease control. Previous researches have also supported these findings 22,23. BMI of most of the patients participating in our study was lying in the range of obese or over weight clearly highlighting the problems related with obesity in these patients. Diabetes and obesity sometimes exist in a positive feedback cycle augmenting each other further.

Despite strict inclusion/exclusion criteria and other strengths of this trial, there were few limitations associated with study design as well. Follow up was not long to see the long term actual effects of the intervention. Only healthy individuals who were able to complete 7000 steps per day were included in this study so results could not be generalized. Sample was drawn from a military hospital which allows increased inclusion of retired or serving soldiers which have a distinct pattern and life style which again decreases the generalizability of this analysis. Number and type of oral hypoglycemic drugs which each individual was taking was not made part of the analysis therefore cause effect relationship of physician led non pharmacological interventions could not be very clear. Future studies with more sophisticated study design and control of confounding factors involving public sector hospital may generate more generalizable results.

\section{CONCLUSION}

This study showed a statistically significant difference in glycemic control of those patients who received physician led life style modification in addition to conventional biological treatment than those who only 
received the routine anti-diabetic medication. Physicians should be trained to impart this sort of education to the diabetic patients in routine diabetic clinics.

\section{CONFLICT OF INTEREST}

This study has no conflict of interest to be declared by any author.

\section{REFERENCES}

1. Uloko AE, Musa BM, Ramalan MA, Gezawa ID, Puepet FH, Uloko AT, et al. Prevalence and risk factors for diabetes mellitus in nigeria: a systematic review and meta-analysis. Diabetes Ther 2018; 9(3): 1307-16.

2. Bullard KM, Cowie CC, Lessem SE, Saydah SH, Menke A, Geiss LS. Prevalence of diagnosed diabetes in adults by diabetes type United States, 2016. Morb Mortal Wkly Rep 2018; 67(12): 359-61.

3. Al Mansari A, Obeid Y, Islam N, Fariduddin M, Hassoun A, Djaballah K, et al. GOAL study: clinical and non-clinical predictive factors for achieving glycemic control in people with type 2 diabetes in real clinical practice. BMJ Open Diabetes Res Care 2018; 6(1): e000519.

4. Sherwani SI, Khan HA, Ekhzaimy A, Masood A, Sakharkar MK. Significance of HbA1c test in diagnosis and prognosis of diabetic patients. Biomark Insights 2016; 11(1): 95-104.

5. Shomali M. Diabetes treatment in 2025: can scientific advances keep pace with prevalence?. Ther Adv Endocrinol Metab 2012; 3(5): 163-73.

6. Raveendran AV, Chacko EC, Pappachan JM. Non-pharmacological treatment options in the management of diabetes mellitus. Eur Endocrinol 2018; 14(2): 31-39.

7. Sanghani NB, Parchwani DN, Palandurkar KM, Shah AM, Dhanani JV. Impact of lifestyle modification on glycemic control in patients with type 2 diabetes mellitus. Indian J Endocrinol Metab 2013; 17(6): 1030-39.

8. Funk M, Taylor EL. Pedometer-based walking interventions for free-living adults with type 2 diabetes: a systematic review. Curr Diabetes Rev 2013; 9(6): 462-71.

9. Lynch EB, Liebman R, Ventrelle J. Design of the Lifestyle Improvement through Food and Exercise (LIFE) study: A randomized controlled trial of self-management of type 2 diabetes among African American patients from safety net health centers. Cont- emp Clin Trials 2014; 39(2): 246-55.

10. Trikkalinou A, Papazafiropoulou AK, Melidonis A. Type 2 diabetes and quality of life. World J Diabetes 2017; 8(4): 120-29.

11. Reusch JE, Manson JE. Management of type 2 diabetes in 2017: Getting to goal. J Am Med Assoc 2017; 317(10): 1015-16.

12. Sanghani NB, Parchwani DN, Palandurkar KM, Shah AM, Dhanani JV. Impact of lifestyle modification on glycemic control in patients with type 2 diabetes mellitus. Indian J Endocrinol Metab 2013; 17(6): 1030-39.

13. Sami W, Ansari T, Butt NS, Hamid MRA. Effect of diet on type 2 diabetes mellitus: A review. Int J Health Sci 2017; 11(2): 65-71.

14. Khan MU. Lifestyle modification in the prevention of type II diabetes mellitus. Oman Med J 2012; 27(2): 170-71.

15. Shera AS, Basit A, Team P. Pakistan's recommendations for optimal management of diabetes from primary to tertiary care level (PROMPT). Pak J Med Sci 2017; 33(5): 1279-83.

16. Lim WY, Ma S, Heng D, Tai ES, Khoo CM, Loh TP. Screening for diabetes with HbA1c: Test performance of HbA1c compared to fasting plasma glucose among Chinese, Malay and Indian community residents in Singapore. Sci Rep 2018; 8(1): 12419.

17. Korkiakangas EE, Alahuhta MA, Husman PM, KeinänenKiukaanniemi S, Taanila AM, Laitinen JH. Pedometer use among adults at high risk of type 2 diabetes, Finland, 2007-2008. Prev Chronic Dis 2010; 7(2): A37.

18. Haq Z, Hafeez A, Zafar S, Ghaffar A. Dynamics of evidenceinformed health policy making in Pakistan. Health Policy Plan 2017; 32(10): 1449-56.

19. Unnikrishnan R, Shah VN, Mohan V. Challenges in diagnosis and management of diabetes in the young. Clin Diabetes Endocrinol 2016; 2(1): 18-23.

20. Dasgupta K, Rosenberg E, Joseph L, Cooke AB, Trudeau L, Bacon SL, et al. Physician step prescription and monitoring to improve ARTERial health (SMARTER): A randomized controlled trial in patients with type 2 diabetes and hypertension. Diabetes Obes Metab 2017; 19(5): 695-704.

21. Sergeant C, Dyson PA. Diabetes and diet: A patient and dietitian's perspective. Diabetes Ther 2018; 9(5): 1733-39.

22. Wang LL, Wang Q, Hong Y, et al. The effect of low-carbohydrate diet on glycemic control in patients with type 2 diabetes mellitus. Nutrients 2018; 10(6): 661.

23. Wilding JP. The importance of weight management in type 2 diabetes mellitus. Int J Clin Pract 2014; 68(6): 682-91. 